\title{
Linking Communities of Practice with Learning Communities in Computer Science Education
}

\author{
Knut Hinkelmann', Kai Holzweißig ${ }^{2}$, Johannes Magenheim², Fabian \\ Probst ${ }^{1}$, Wolfgang Reinhardt ${ }^{2}$ \\ ${ }^{1}$ University of Applied Sciences Northwestern Switzerland, \\ Institute of Management and Business Information Systems \\ Olten, Switzerland \\ $\{$ knut.hinkelmann, fabian.probst $\} @$,fhnw.ch \\ ${ }^{2}$ University of Paderborn, Institute of Computer Science \\ Paderborn, Germany \\ $\{k w h, j s m, w o l l e\} @ u p b . d e$
}

\begin{abstract}
MoKEx (Mobile Knowledge Experience) is an international project in cooperation with universities and industrial partners. The project focuses on didactical, organizational and technical problems with regard to blended learning and knowledge management scenarios. In a project-based learning approach students of two different universities are being prepared for their future work. They are working on real-world problems in an interdisciplinary team and are collaborating within a geographically and temporally separated team. Therefore means for communication and collaboration over the Internet must be provided. From the didactical perspective the aspects of autodidactic education and team learning are playing an important role, while teachers are acting primarily as coaches. In the meantime the results of the first execution of the project have been enhanced and put into operation by the companies and a second execution has been started.
\end{abstract}

\section{Description and Intention of MoKEx}

MoKEx consists of two projects, which started one after another each lasting one year. MoKEx I started in October 2004. It was a general task of the project, given by all industrial partners, to develop and implement software in order to improve elearning within the companies. A major curricular task of the MoKEx project was to improve computer science education (CSE) on a higher-education level by embedding informatics seminars at universities in real-life scenarios. The paper

Please use the following format when citing this chapter:

Hinkelmann, K., Holzweißig, K., Magenheim, J., Probst, F., Reinhardt, W., 2006, in Intemational Federation for Information Processing, Volume 210, Education for the $21^{\text {st }}$ Century-Impact of ICT and Digital Resources, eds. D. Kumar, and Turner J., (Boston: Springer), pp. 83-92. 
describes the accordance of the curricular concept of MoKEx with demands of international CSE-curricula and current learning theories and outlines the organizational and collaborative structures of the project.

\subsection{Partners}

The MoKEx project is an interdisciplinary project of the following scientific and economic partners: University of Paderborn, Germany, University of Applied Sciences Northwestern Switzerland, Switzerland, STEAG AG, Switzerland, Magh \& Boppert, Germany, SBB AG, Switzerland, Swissmem, Switzerland, Swisscom Mobile $A G$, Switzerland, SAQ Qualicon $A G$, Switzerland and Stahl Gerlafingen $A G$, Switzerland.

\subsection{Expectations, Objectives and Content}

With regard to constructivist theories and their application in CSE [1] students' learning activities in the MoKEx project are situated, self-directed, investigating and oriented to the practice of computer science. Students learn not only to develop informatics systems as a subject matter of software engineering but also to use them as co-operative media (e.g. IDE, CMS) that support collaborative working in a distributed learning group.

The informatics competencies students should achieve in the project must represent the handling of an existing software product of a customer as well as the process of software development. We have to take into consideration the process of the systems' construction and its modeling as well as the process of re-engineering of an existing system for the needs of the industrial partners. Therefore, requirements analysis, including the analysis of business processes of the industrial partners, is an important issue of the project.

The MoKEx project combines practical education with up-to-date research in information technology and knowledge management. The industrial partners of MoKEx are active in the knowledge-intensive service sector. Because of market dynamics they have to undergo permanent changes and adaptation in order to react to their customers needs and to be competitive. Organizational structure, processes and service supply (customer care, retail sales, corporate business sales) are constantly adapted. This demands high standards for knowledge management, professional training and controlling of training activities.

From this, research questions arise that are both highly interesting and extremely relevant in practice. Through their project work the students, on the one hand, get insights in the everyday demands of customer-oriented service companies and, on the other hand, are contributing to the development of both science and economy.

Thus, the MoKEx project meets the demands of various international computer science curricula with regard to the subject areas, the informatics methods and last but not least the teaching and learning methods. Denning, who analyzed current CSE-curricula defines "Great Principles of Computing" scaffolding for a curriculum [2]. They include "Design Principles" such as complexity and performance, and of "Computing Mechanics" such as computation, communication or coordination. 
They also include "Computing Practices" such as programming, engineering systems, modeling, innovating and applying, as well as "Core Technologies" such as architecture, algorithms, databases and networks. Students in the MoKEx-Project have to deal with parts of all these subject areas of informatics when they solve project-oriented problems (see Section 3.2).

Denning, as well as the various CSE-curricula, also emphasizes the importance of "working with practitioners in application domains to produce computing systems that support their work" [2, p. 4].

Also the IEEE /ACM-curriculum stresses that CSE-curricula "must include exposure to aspects of professional practice as an integral component" [3, p. 14]. Besides technical skills the IFIP/UNESCO-Curriculum intends to achieve "personal and interpersonal skills" such as "communication, team work, critical thinking, leadership, working with users, interdisciplinary environments, written specifications and documentation, dealing with ambiguity" [4, p. 33]. Furthermore, the IFIPcurriculum requires broadening the perspectives and context by linking informatics with other disciplines. These are also relevant issues of the didactical concept of MoKEx.

\subsection{Organizational structure}

The integration of this educational element in the curricula of the participating universities slightly differs:

- At the University of Paderborn (UPB) the project is embedded in the last two semesters. Students are working for one day per week in the project. In parallel they have to attend regular courses. The aim of the project work is to integrate, apply and strengthen competences, the students already have acquired during regular lessons and in smaller projects.

- At the University of Applied Sciences Northwestern Switzerland (FHNW) the project starts after three semesters. During 16 weeks the students are engaged for four days a week directly at the involved companies. As the students are in the middle of their education, acquisition and development of specialized knowledge and new competences are important aspects of project work. Another very important objective is to gain practical experiences in project management, a topic the students already know from former lessons. In the project, however, they have to cope with real-world problems like interview partners not being available, changes in schedules, modification of requirements etc. FHNW provides a coaching day once per week, where the students can ask for support from the lecturers.

MoKEx is applied as an interdisciplinary, geographical and temporally separated project. While scientific and applied scientific competencies are split to the German University of Paderborn and the Swiss University of Applied Sciences Northwestern Switzerland, all project partners are Swiss businesses. Magh \& Boppert arises as technology provider for German and Swiss students. The organization of both, MoKEx I and MoKEx II is shown in Figure 1. 


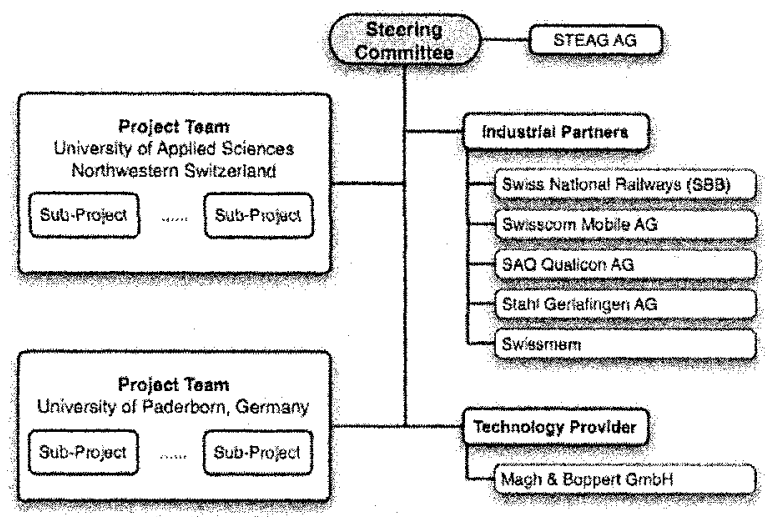

Figure 1: Organization Chart MoKEx of the Project

The Swiss STEAG AG supervises the steering committee. Each participating country has to contribute to the steering committee with a scientific leader and an overall team leader. The project group is split in two teams: the project team at the UPB and that at the FHNW. Each team has to meet the demands of the industrial partners.

The time flow of both projects is organized in six consecutive stages:

- Initial stage: The initial phase of MoKEx I and II is characterized by the buildup of competencies by all parties involved in the project. In this initial stage all project partners are to define their expectations and hopes of what the project will deliver.

- Evaluation stage: This stage has changed its importance from MoKEx I to MoKEx II. Whereas this stage was of nearly no importance to the students themselves in MoKEx I, it is one of the most significant stages in MoKEx II. During this stage the students have to make requirements analyses at the industrial partners' sites and build up communication networks in personal responsibility. Furthermore all students have to present their findings in a group workshop.

- Specification stage: This stage deals with the development of solution approaches to meet the industrial requirements. All approaches and findings are written down in a document of specification, which is delivered to the industrial partners.

- Realization stage: A prototype that meets the requirements of the industrial partners and the approaches of the preceding stage is developed in this phase.

- Test stage: The deliverables are tested and afterwards presented to all project partners.

- Outcome and Presentation stage: In this phase all outcomes of the project are embraced in a final presentation with the Project Partners. At a showroom, members of all sub-projects are to speak about their work and outcomes. 


\subsection{Collaborative Structure}

Due to the geographical and temporally separated teams, it was necessary to place great importance on assembling a well-working communication network for both industrial partners and the particular teams. For the external presentation of the project and the industrial partners the FHNW set up a project platform on which final documents and protocols were stored. The steering committee used this platform for organization and objectives balancing.

The local work of Swiss and German students was assisted by CVS systems located at the technology provider Magh \& Boppert. The students made all responsibility assignments in the particular sub-projects with complete personal responsibility. This was made to simulate real-world scenarios and to engender competencies in project management with the students. Information exchange between German and Swiss students in different dependent sub-projects was realized using standard instant messenger tools, e-mail, IRC and phone. For the actual running project MoKEx II, the application of groupware tools as shared whiteboards is envisaged.

As in any project, documentation is one of the most important things to think about in MoKEx I and II. For any academic project it is necessary to evaluate the individual effort of each participant. In the case of MoKEx I this means that every student had to write down what he or she did in the project period. Since it was difficult for the students in MoKEx I to reflect their effort over a past year, the scientific head decided to use weblogs in MoKEx II. With the help of these individual weblogs the students are forced to reflect their own learning processes and to deal actively with occurring problems in the project work.

\section{Educational Concept}

MoKEx follows a project-based learning approach. This didactical concept allows students to gain competencies that cannot be obtained by traditional lectures or seminars. According to [5], project-based learning situations are characterized by authentic questions or problems and investigations that enable students to formulate and refine specific questions, based on original data. Moreover, project-based learning is result-oriented (artifacts, system implementations) and usually a community of learners and trainers collaborate. In MoKEx additional aspects extend the project-based learning approach:

- The team members exhibit interdisciplinary skills. The project partners from UPB provide computer science competencies in system development and technical implementation. The core competencies of FHNW are more application oriented; therefore the FHNW team focuses questions of integration and interaction with the industrial partners. The combination of theses competencies, complemented by the educational knowledge of STEAG AG and Magh \& Boppert, builds an interdisciplinary team, which assures an integrated solution. 
- The project team covers the whole spectrum from research to practice. UPB as a university is on the research side of the spectrum, and the industrial partners represent practice. FHNW as a university of applied sciences is a kind of mediator between both extremes. Regular meetings and information exchange between sub-projects stimulate comprehension and consideration of both theoretical and practical aspects in the project results.

- The project asks for specific professional competencies. Among others, skills in programming distributed systems, database management, mobile communication and screen design are required to solve the problems of the industrial partners. Part of this knowledge is provided by antecedent regular courses. In addition missing knowledge has to be obtained in a "Continuous and Cooperative Self-qualification and Self-organization (CoCoSS)" learning process [6]. This includes the independent planning and execution, as well as the continuous renewal and implementation, of learning. In MoKEx students use workshops as one important method to develop knowledge in a cooperative way.

- Due to the involvement of the industrial partners, methodological competence in project management, user requirement analysis and presentation skills are applied in the context of a real situation. Moreover the project offers the possibility to develop the student's social competence, as they are forced to negotiate not only working conditions and incentives but also solutions with the industrial partners. In order to fulfill theses ambitious tasks, periodical plenary sessions are organized to exchange experiences with colleagues from other projects. In addition teachers are available on demand for coaching.

- The MoKEx team is working geographically and temporally separated. Therefore the requirements regarding documentation of the project and knowledge transfer within the team are quite high and adequate means for synchronous and asynchronous communication must be provided.

It is the goal of all these measures to create a real-world scenario in which the students gain important competencies for their future work. Similar goals have been focused by the CommSy project on the University of Hamburg, described in [7].

\section{Project Outcomes}

\subsection{Technical Outcomes}

\subsubsection{Mobile Delivery Server}

Traditional e-learning scenarios are based on client/ server architecture and are not primarily designed for mobile scenarios. To offer e-learning in mobile scenarios, difficult technical challenges involving platform heterogeneity, wireless communication protocols, screen resolution and other usability matters must be dealt with. Ultimately, e-learning objects have to be dynamically converted and 
customized according to the target platform. This applies to multimedia content, as well as to the native format (e.g. XML) in which the content is stored. The "Mobile Delivery Server" (MDS), is our advanced software approach to resolve some of the problems and limitations described above. The MDS (cf. Figure 2(a)) introduces a new middle layer service for the technical needs of mobile e-learning scenarios. The MDS also provides compatibility of learning objects with a broad variety of mobile clients and allows the distribution of platform-dependent players.

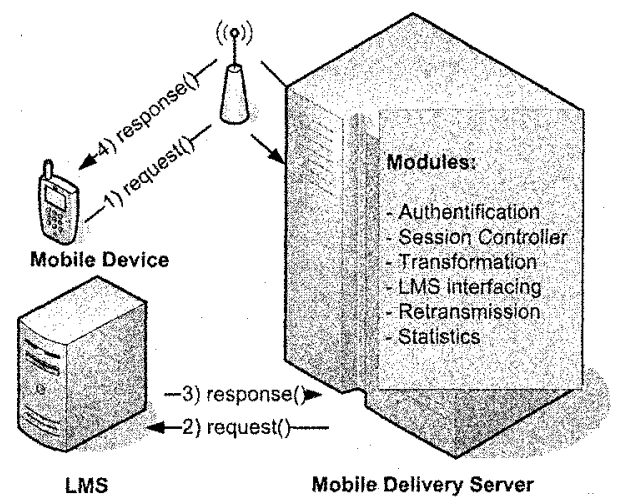

(a) Architecture of the MDS

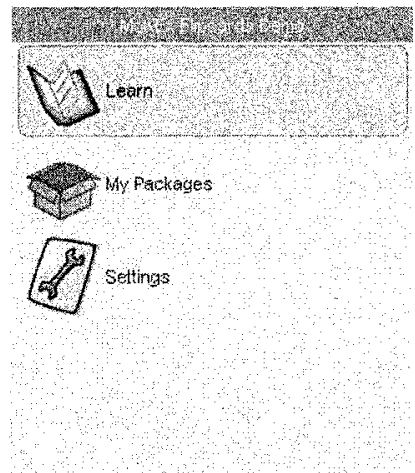

Exit

(b) Screenshot of Flipcard-Player

Figure 2: Developed Mobile Delivery Server and Flipcard-Player

\subsubsection{Flipcard-Player}

The Flipcard-Player is mobile client software for the use of special e-Learning contents. The learning objects to be used with this software are simple flipcards as known from traditional learning scenarios. Each flipcard contains a question on the frontside and the corresponding answer on the backside. By walking through the deck of flipcards delivered by the MDS, the player enables students to learn factual knowledge (e.g. vocabulary words, scientific formulas or sales arguments). One possible application of our developed technology within the educational area is student training, which will be evaluated by Swissmem. During the evaluation, the students of different vocational schools will receive the Flipcard-Player and the learning objects via WAP, Bluetooth and IRDA. Swissmem will provide content via an e-tutor LMS. The learning objects will cover exam-related materials the students are responsible for learning. The evaluation will provide us with information about the technical and educational aspects of this specific mobile learning scenario. The MDS was successfully tested by using a prototype of a Flipcard-Player for cell phones. A second field test will be carried out by Swisscom Mobile, and will also involve students (cf. Figure 2(b)). 


\subsubsection{Knowledge-Database}

Another sub-project of MoKEx dealt with the development of a knowledge database. Furthermore the integration into an electronic learning management system (LMS) etutor provided by Magh \& Boppert was realized. Using the knowledge database, every user of the LMS has the ability to contribute to a business internal compilation of explicit knowledge. During the specification and realization of the architectural concept an extensive authoring process for knowledge database articles was developed and realized. Figure 3 shows the authoring process mentioned above.

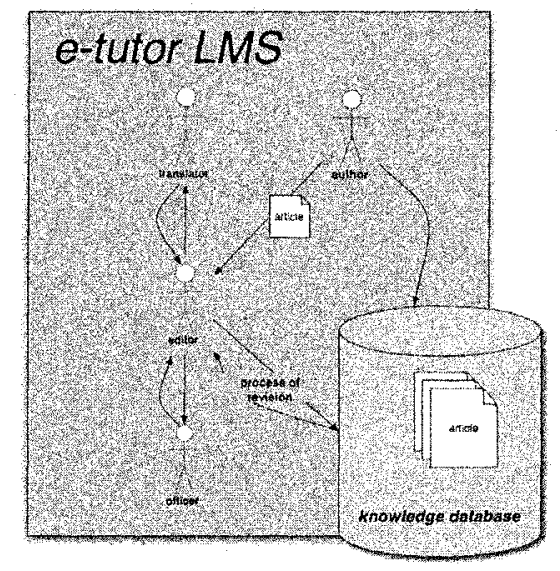

Figure 3: Authoring process for articles in the knowledge database

The developed knowledge database knows four types of users: authors, editors, officers and translators. To assure high-quality articles in the database, all new or modified articles go through an authoring process. The articles are, based on the taxonomy path they are in, sent to an editor who reviews the article concerning syntactic problems and faults. Subsequently the article is passed to an officer with specialist knowledge who reviews the article concerning textual correctness and thereafter returns the reviewed article to the editor. Following this, the article is passed to one or more translators who produce several multi-lingual versions of the article. Finally the editor releases all multi-lingual versions of the article to the public view of the knowledge database. Every user can make annotations and extensions to the public articles, which leads to a new authoring process that follows the same process.

\subsection{Individual Outcomes}

A lot of the informatics-related knowledge and interpersonal skills mentioned above were imparted by the MoKEx project. According to the criteria of an IFIP Working Conference on "Information and Communication Technologies (ICT) and Real-life 
Learning" [8] the MoKEx project realizes several interesting concepts of practicerelated learning in CSE with regard to individual and institutional aspects:

- The institutional outcomes mainly affect the improvement of teaching and learning in computer science courses, but they also are relevant for the student's competencies. The project offers integrated working and learning in real-life situations, which was highly motivating for the students. Tutors and teachers got a more advisory role focusing on the project management and supporting the process of knowledge acquisition. Interdisciplinary knowledge exchange was enabled by co-operation between students of different universities and faculties.

- Individual outcomes for the students include the following: The students have gained a broad understanding of project management issues, as well as competencies in communication and documentation. The interaction with our partners from industry fostered the development and practice of social skills. Competencies in autodidactic learning and knowledge transfer were enforced with workshop and online collaboration sessions. Technical skills have been well trained by software design and the implementation of prototypes.

As already mentioned in Section 1 , the students deal with all subject areas according to Denning's principles of computing [2]:

- Design Principles: The MoKEx project provides industrial partners with software products for professional use and fosters international co-operation with business and industry. In comparison with traditional teaching, the students obtained a more decisive and managing role in the project because they are responsible for the project outcome with respect to both time schedule and software design. Co-operation between students from both technical and business faculties was valuable in requirements engineering and systems design.

- Computing Mechanics: The project uses Information and Communication Technology (ICT) to enable collaborative learning in a distributed working group and provides the students with experiences concerning the effective use of ICT-environments for these purposes.

- Computing Practices: Co-operation between universities and business partners leads to a more practice-oriented concept of teaching software engineering.

- Core Technologies: Technical skills involved distributed systems, database management, mobile communication and usability matters of mobile devices.

\subsection{Evaluation of outcomes}

During the project the progress of the students is assessed using weekly progress reports and in coaching sessions. Periodic presentations permit knowledge exchange between students and give evidence on student progress for the lectures. In addition, new forms of ICT-supported project assessment like weblogs edited by the students are tested. The evaluation of the project outcomes differs between UPB and FHNW:

- At UPB each student group has to deliver the software system together with a specification and design document and make a final presentation.

- The students of FHNW have to keep an account of the project issues. This project handbook together with a final report is evaluated by two lecturers who give grades for technical and project management outcomes, respectively. 


\section{Conclusions and further work}

Based of the experiences from MoKEx I, some improvable points were discovered from the pedagogical perspective:

The directives for the assessment were synchronized for the second execution of the project. For MoKEx II, we introduced an initial requirements analysis phase (see above), in which students start by interviewing the industrial partners and exposing potential problems. For internal communication and purposes of self-reflection of their learning processes, a BLOG-Server is introduced in the second execution.

Real-world projects bring along a complexity in planning and execution that cannot be conveyed by traditional education methods. MoKEx combines established existent principles from CSE with new educational methods. Cooperative and selforganized work in an interdisciplinary team within the existing fields of research and application and the involvement of industrial partners are key elements of the didactical concept of MoKEx. The comparison with international concepts has shown that the project meets the various demands of modern CSE. Moreover the connection between higher education and industry generates a win-win situation, where students get insights in everyday working situations and on the other hand they contribute to the development of an organization and the economy as a whole.

\section{References}

1. D. Hung. Forging Links Between "Communities of Practice" and Schools Through Online Learning Communities: Implications for Appropriating and Negotiating Knowledge. In International Journal on E-Learning, volume 1(2), pages 23-33. AACE, 2002.

2. P.J. Denning. Great Principles in Computing Curricula. http://cne.gmu.edu/pjd/PUBS/GP_curr_sigcse.pdf, Proofed 12/27/2005.

3. Joint Task Force on Computer Engineering Curricula IEEE ACM. Software Engineering 2004 - Curriculum Guidelines for Undergraduate Degree Programs in Software Engineering, http://sites.computer.org/ccse/SE2004Volume.pdf, August 2004.

4. F. Mulder and T. van Weert. Informatics Curriculum Framework 2000 for Higher Education Edited by International Federation for Information Processing (IFIP) / UNESCO. http://www.ifip.org/pdf/ ICF2001.pdf, 2000.

5. R. P. Ferretti and C. M. Okolo. Authenticity in learning: Multimedia design projects in the social studies for students with disabilities. Journal of Learning Disabilities, 29(5):452, 1996.

6. K. Ehrlich, W. Gabriel, J. Heier, V. Rentsch, M. Sabel, P. Schneider, and H.-J. Walter. Lernen und Arbeiten im Team - Leitfaden: Kontinuierliche und Kooperative Selbstqualifikation und Selbstorganisation (KoKoSS). Bonifatius Verlag Paderborn, 1993.

7. M. Janneck and W.-G. Bleek. Pro ject-based Learning with CommSy. In G. Stahl, editor, Proceedings of the CSCL 2002 Conference, 2002.

8. IFIP. IFIP Working Conference on "Information and Communication Technologies (ICT) and Real-life Learning" Proofed 6th - 10th December 2004., http://www.cetis.hvu.nl/publicaties/MelbourneCallforPapersDef.doc 